\title{
Percutaneous Coronary Intervention Versus Medical Therapy for Chronic Total Occlusion of Coronary Arteries: A Systematic Review and Meta-Analysis
}

\author{
Ka Hou Christien $\mathrm{Li}^{1,2,3} \cdot$ Ka Hei Gabriel Wong ${ }^{1,2} \cdot$ Mengqi Gong ${ }^{4} \cdot$ Tong Liu ${ }^{4}$ • Guangping $\mathrm{Li}^{4} \cdot$ Yunlong Xia ${ }^{5}$. \\ Jeffery $\mathrm{Ho}^{2,6}$ • Luis Nombela-Franco ${ }^{7}$. Abhishek C. Sawant ${ }^{8}$. Simon Eccleshall ${ }^{9}$. Gary Tse ${ }^{1,2}$. \\ Vassilios S. Vassiliou ${ }^{9,10,11}$
}

Published online: 9 August 2019

(C) The Author(s) 2019

\begin{abstract}
Purpose of Review Chronic total occlusion (CTO) of the coronary arteries is a significant clinical problem and has traditionally been treated by medical therapy or coronary artery bypass grafting. Recent studies have examined percutaneous coronary intervention (PCI) as an alternative option.

Recent Findings This systematic review and meta-analysis compared medical therapy to PCI for treating CTOs.

Summary PubMed and Embase were searched from their inception to March 2019 for studies that compared medical therapy and PCI for clinical outcomes in patients with CTOs. Quality of the included studies was assessed by Newcastle-Ottawa scale. The results were pooled by DerSimonian and Laird random- or fixed-effect models as appropriate. Heterogeneity between studies and publication bias was evaluated by $I^{2}$ index and Egger's regression, respectively. Of the 703 entries screened, 17 studies were included in the final analysis. This comprised 11,493 participants. Compared to PCI, medical therapy including randomized and observational studies was significantly associated with higher risk of all-cause mortality (risk ratio (RR) 1.99, 95\% CI 1.38-2.86), cardiac mortality (RR 2.36 (1.97-2.84)), and major adverse cardiac event (RR 1.25 (1.03-1.51)). However, no difference in the rate of myocardial infarction and repeat revascularization procedures was observed between the two groups. Univariate metaregression demonstrated multiple covariates as independent moderating factors for myocardial infarction and repeat
\end{abstract}

G.T. and V.S.V. are joint senior authors

This article is part of the Topical Collection on Evidence-Based Medicine, Clinical Trials and Their Interpretations

Electronic supplementary material The online version of this article (https://doi.org/10.1007/s11883-019-0804-8) contains supplementary material, which is available to authorized users.

Vassilios S. Vassiliou

V.Vassiliou@uea.ac.uk

1 Department of Medicine and Therapeutics, Faculty of Medicine, Chinese University of Hong Kong, Hong Kong, SAR, People's Republic of China

2 Li Ka Shing Institute of Health Sciences, Faculty of Medicine, Chinese University of Hong Kong, Hong Kong, SAR, People's Republic of China

3 Faculty of Medicine, Newcastle University, Newcastle, UK

4 Tianjin Key Laboratory of Ionic-Molecular Function of Cardiovascular Disease, Department of Cardiology, Tianjin Institute of Cardiology, Second Hospital of Tianjin Medical University, Tianjin 300211, People's Republic of China
5 Department of Cardiology, First Affiliated Hospital of Dalian Medical University, Dalian, China

6 Department of Microbiology, The Chinese University of Hong Kong, Hong Kong, SAR, People's Republic of China

7 Cardiology Department, Instituto Cardiovascular, Hospital Clínico San Carlos, IdISSC, Madrid, Spain

8 Division of Interventional Cardiology, Banner University Medical Center, Phoenix, AZ, USA

9 Norfolk and Norwich University Hospital and Norwich Medical School, University of East Anglia, Norwich, UK

10 Royal Brompton Hospital and Imperial College London, London, UK

11 Bob Champion Research and Education, Second Floor, University of East Anglia, Norwich Research Park, Norwich NR4 7TJ, UK 
revascularization but not cardiac death and all-cause mortality. However, when only randomized studies were included, there was no difference in overall mortality or cardiac death. In CTO, when considering randomized and observational studies, medical therapy might be associated with a higher risk of mortality and myocardial infarction compared to PCI treatment.

Keywords Chronic total occlusion $\cdot$ Mortality $\cdot$ Adverse outcomes

\section{Introduction}

A chronic total occlusion (CTO) is characterized by the complete or near complete occlusion of a coronary artery with no or minimal downstream flow (TIMI flow grade 0 or 1) for a period longer than 3 months [1]. Among patients with coronary heart disease who are referred for coronary angiography, a large proportion ranging from 18 to $52 \%$ are found to have CTOs [2-4]. However, only a small proportion of these patients subsequently undergo percutaneous coronary intervention (PCI) $[2,5]$ with approximately one-tenth of CTO patients in North America undergoing PCI in the end $[3,6,7]$. Therefore, despite the rising popularity of percutaneous intervention for this group of CTO patients, the vast majority are either treated with medical therapy or coronary artery bypass grafting (CABG) [6]. However, it is recognized that patients with CTOs have a poorer prognosis when compared to those with coronary disease but without CTOs $[8,9]$. This is often exacerbated by the fact that many patients with CTO tend to be asymptomatic, which leads to a delay in the diagnosis, investigations, and subsequent treatment [3] which may partly at least explain the broad prevalence range.

Hence, despite guidelines $[1,10,11]$ recommending consideration of $\mathrm{PCI}$ in patients with $\mathrm{CTO}$ to improve survivability and quality of life, the prevalence of PCI in CTO patients remains low. This trend is potentially further reinforced by the 2016 EXPLORE trial [12]. Observation and randomized studies appear

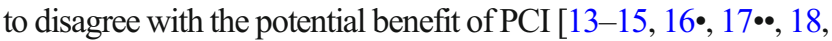
$19 \cdot 0$. The issue thus of whether PCI or medical therapy should be the preferred management option in patients with CTOs remains controversial. This is also further compounded by potential sexbased differences in CTO management [20]. As such, this systematic review and meta-analysis seeks to combine all available cohort studies involving head-to-head comparison between PCI and medical therapy in CTO patients to offer a more comprehensive understanding. Further multivariate meta-regression analysis has also been used to help identify covariates that can potentially moderate outcome measures between the two interventions.

\section{Methods}

\section{Search Strategy, Inclusion and Exclusion Criteria}

This study was conducted according to the Preferred Reporting Items for Systematic Reviews and Meta-Analyses
(PRISMA) statement. PubMed and Embase were searched for studies that compare medical therapy to $\mathrm{PCI}$ in patients with CTO. The following search terms were used for both databases: [(chronic total occlusion) AND (((percutaneous coronary intervention) OR (revascularization)) AND ((optimal medical therapy) OR (medical therapy)))]. The search period was from the beginning of the database through to March 1, 2019 without language restrictions. Both fully published studies and abstracts were used. The following inclusion criteria were used: (1) studies involving patients with CTO requiring either medical therapy or PCI; (2) measured and compared the difference in outcome between the two procedures, medical therapy and PCI. These outcomes assessed included all-cause mortality, cardiac death, cerebral vascular accident (CVA), myocardial infarction (MI), repeated revascularization, major adverse cardiac event (MACE), and major adverse cardiac and cerebrovascular events (MACCEs). MACE was defined as a composite of non-fatal stroke, non-fatal MI, and cardiovascular death, whereas MACCE was defined as a composite of allcause mortality, MI, stroke, or ischemia-driven target vessel revascularization.

The Newcastle-Ottawa Quality Assessment Scale (NOS) and Cochrane risk of bias tool were used for quality assessment of the included studies. The NOS system evaluated the categories of study participant selection, results comparability, and quality of the outcomes. Specifically, the following characteristics were assessed: (1) representativeness of the exposed cohort; (2) selection of the non-exposed cohort; (3) ascertainment of exposure; (4) demonstration that outcome of interest was not present at the start of study; (5) comparability of cohorts based on study design or analysis; (6) assessment of outcomes; (7) follow-up periods that were sufficiently long for outcomes to occur; (8) adequacy of follow-up of cohorts. This scale varied from zero to nine stars, which indicated that studies were graded as poor quality if the score was $<5$, fair if the score was 5 to 7 , and good if the score was $>8$. Studies with a score equal to or higher than 6 were included. The details of the NOS quality assessment and Cochrane risk of bias assessment for randomized controlled trials are shown in Supplementary Table 1 and Supplementary Fig. 1.

\section{Data Extraction and Statistical Analysis}

Data from different studies were entered in pre-specified spreadsheets in Microsoft Excel. All potentially relevant 
studies were retrieved as complete manuscripts, which were assessed fully to determine their compliance with the inclusion criteria. We extracted the following data from the included studies: (1) publication details: last name of first author, publication year, and locations; (2) study design; (3) outcome(s); (4) characteristics of the population including sample size, gender, age, and number of subjects. Two reviewers (K.H.G.W. and K.H.C.L) reviewed each included study independently. Disagreements were resolved by adjudication with input from a third reviewer (G.T.).

Heterogeneity across studies was determined using Cochran's $Q$ value and the $I^{2}$ statistic from the standard $\chi^{2}$ test. Cochran's $Q$ value is the weighted sum of squared differences between individual study effects and the pooled effect across studies. The $I^{2}$ statistic from the standard $\chi^{2}$ test describes the percentage of variability in the effect estimates resulting from heterogeneity. $I^{2}>50 \%$ was considered to reflect significant statistical heterogeneity. The random-effects model using the inverse variance heterogeneity method was used with $I^{2}>50 \%$. To locate the origin of the heterogeneity, sensitivity analysis excluding one study at a time was also performed. Funnel plots showing standard errors or precision against the logarithms of the odds ratio were constructed. The Begg and Mazumdar rank correlation test and Egger's test were used to assess for possible publication bias. Possible associations between population co-variables and study outcomes were explored using multivariate meta-regression. To account for missing data, we used mean imputation $(<10 \%$ missing) or random imputation (> 10\% missing). All statistical analysis was conducted using Review Manager 5.3 for MacOS and Comprehensive Meta-Analysis (CMA) version 3.0 (Biostat, Inc., Englewood, NJ, USA). Statistical significance was set as $P$ value of less than 0.05 .

\section{Results}

\section{Patient Baseline Characteristics}

A flow diagram detailing the search and study selection process is illustrated in Fig. 1. In the final meta-analysis, a total of 15 cohort studies and 3 randomized controlled trials involving 11,928 patients between 2011 and 2019 met our selection

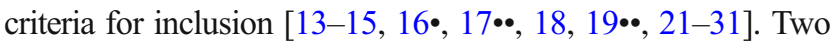
studies included the same population $[22,31]$ and therefore we only included the most recent one [31] reducing our number of studies to a total of 17 , involving 11,493 patients. The mean age of the included population was 57.4 years, of the majority being male $(81.8 \%)$. The baseline characteristics of all patients and follow-up duration based on individual studies are summarized in Table 1. However, only the baseline characteristics for 13 (out of 17) studies were available for inclusion in Table $1[13$, $14,16 \bullet 17 \bullet \bullet, 18,19 \bullet \cdot, 21-25,27,29,31]$. This is due to the lack of sufficient data provided by the remaining four studies $[15,26,28,30]$. Furthermore, the baseline characteristics included in three studies $(*)$ utilized that of the overall population as the studies pooled the baseline characteristics of two or more intervention groups (e.g., CABG and PCI) together [23, 25, 27] (Table 1). Nonetheless, sufficient intervention-specific data was still provided by all 17 studies for effective pooling of outcome measures. Outcome measures pooled in this meta-analysis include (1) all-cause mortality, (2) cardiac death, (3) CVA/stroke, (4) MI, (5) repeat revascularization, (6) MACE, and (7) MACCE.

\section{Medical Therapy Versus PCI in CTO Patients: All-Cause Mortality}

A total of 14 out of 17 studies reported all-cause mortality in CTO patients after medical therapy or PCI $[13-15,16 \bullet, 17 \bullet$, $18,19 \bullet \cdot, 23-27,30,31]$. Of these, only two studies reported in favor of medical therapy $[15,19 \bullet \bullet]$ while the remaining 12 reported in favor of PCI. Pooled analysis of all the included studies demonstrated that patients with CTO treated with medical therapy have a significantly higher risk of all-cause mortality when compared to the PCI group (RR 1.99, 95\% CI $1.38-2.86, P=0.0002$; Fig. 2a). However, what is important to recognize here is that there is a significant disagreement with regard to the observational and randomized studies. The observational studies significantly favor PCI (RR 2.09, $1.40-3.10, P=0.0003$ ) while the randomized studies showed a non-significant improvement in mortality (RR 1.41, 0.772.61, $P=0.27$ ), indicating that perhaps the current randomized studies do not have sufficient power to confirm a benefit, which is smaller than what is observed in the cohort studies. $I^{2}$ was $89 \%$ across all studies, indicating a high degree of heterogeneity. In order to locate the origin of the heterogeneity, sensitivity analysis excluding one study at a time was

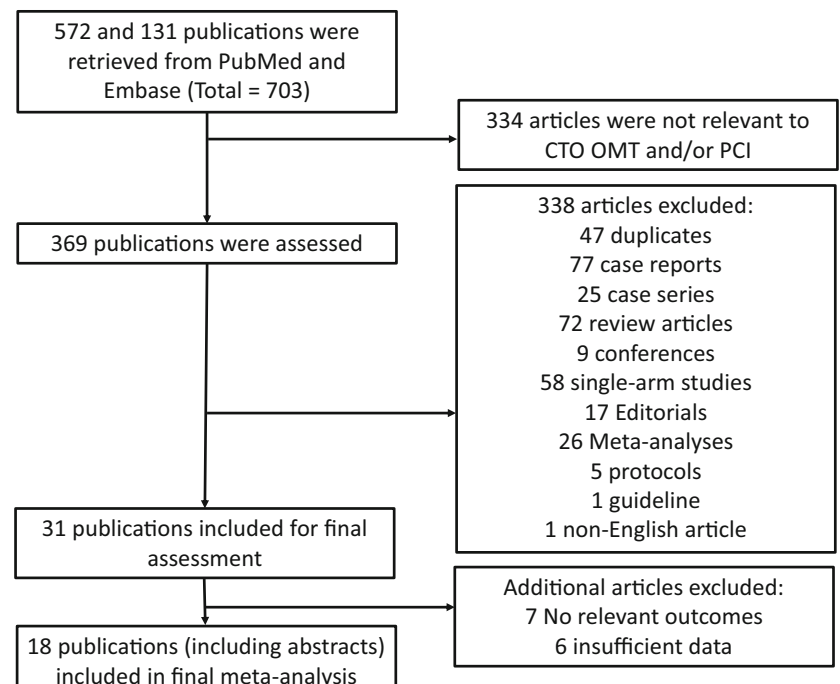

Fig. 1 PRISMA flow diagram for the study selection process 


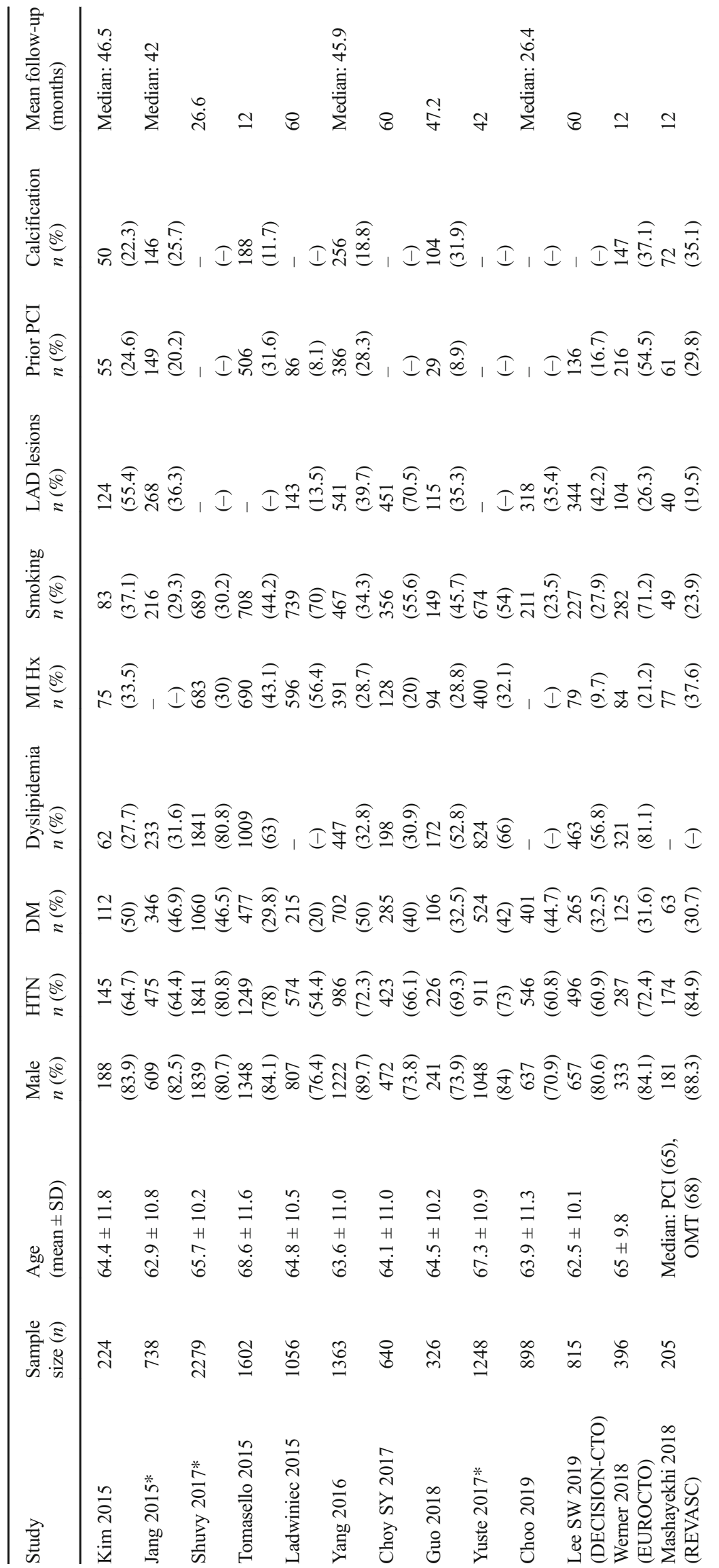


performed. Doing so did not significantly alter the overall heterogeneity. In addition, the results of Egger's test showed no evidence of publication bias (Egger's regression test $P=$ 0.13; Fig. 3a).

\section{Medical Therapy Versus PCI in CTO Patients: Cardiac Mortality}

A total of 11 out of 17 studies reported cardiac mortality in CTO patients $[13,16 \bullet, 17 \bullet \bullet, 19 \bullet \bullet, 21,23-26,29,31]$. All studies included favored the use of PCI apart from Werner et al. [19*0]. Pooled analysis of the included studies demonstrated that patients with CTO treated medical therapy had significantly higher risk of cardiac mortality when compared to the use of PCI (RR 2.36, 95\% CI 1.97-2.84, $P<0.00001$; Fig. 2b). However, the discrepancy between observation and randomized studies existed. While in observation studies there was a very positive improvement seen with PCI (RR 2.42, 95\% CI 2.00-2.91, $P<0.00001)$, there was no significant difference observed with the randomized controlled trials (RCTs) (RR $1.57,95 \%$ CI $0.70-3.51, P=0.27$ ). Nonetheless, the relative risk of 1.57 could still suggest that the RCT even when pooled remained underpowered. $I^{2}$ was $23 \%$ across all studies, indicating a low degree of heterogeneity. Furthermore, results from Egger's test showed no evidence of publication bias (Egger's regression test $P=0.92$; Fig. 3b).

\section{Medical Therapy Versus PCI in CTO Patients: Myocardial Infarction}

A total of 10 studies reported MI as an outcome in CTO patients undergoing either medical therapy or PCI [13, $17 \bullet \bullet, 19 \bullet \bullet, 21,23-26,29,31]$. Three out of 10 studies reported in favor of medical therapy $[17 \bullet \bullet, 19 \bullet \bullet, 23]$. Pooled analysis of the included studies showed that medical therapy was not significantly associated with a higher risk of MI when compared to the PCI group (RR 1.65, 95\% CI 0.97-2.78, $P=0.06$; Fig. 2c). However, when only RCTs were considered, medical therapy showed a non-statistical improvement over PCI (RR $0.73,95 \%$ CI $0.44-1.19, P=0.21)$. Significance was only achieved during pooled analysis of observational studies, favoring the PCI group (RR 2.04, 95\% CI 1.31-3.20, $P=0.002$ ). $I^{2}$ was $74 \%$ across all studies, indicating a high degree of heterogeneity. Sensitivity analysis excluding one study at a time was performed to locate the origin of the heterogeneity which did not significantly alter the overall heterogeneity. Results from the Egger's test showed no evidence of publication bias (Egger's regression test $P=$ 0.95; Fig. 3c).

\section{Medical Therapy Versus $\mathrm{PCl}$ in CTO Patients: Repeated Revascularization}

A total of nine studies were included for reporting repeated revascularization in CTO patients with either medical therapy or PCI $[13,16 \bullet, 17 \bullet \bullet, 18,21,23,24,26,31]$. Of these, five studies reported in favor of medical therapy $[13,16 \bullet, 17 \bullet \cdot, 21$, 26]. A pooled analysis of the included studies demonstrated that the use of medical therapy is associated with lower risk of repeat revascularization (RR $0.93,95 \%$ CI $0.67-1.29, P=$ 0.67 ; Fig. 2 d). While observational studies showed a nonstatistical preference for OMT (RR 0.85, 95\% CI 0.59-1.21, $P=0.36$ ), the randomized studies showed a non-statistical reduction of revascularization with PCI (RR $1.87,95 \%$ CI $0.41-$ $8.58, P=0.42) . I^{2}$ was $84 \%$ across all studies, indicating a high degree of heterogeneity. Sensitivity analysis excluding one study at a time was performed to locate the origin of the heterogeneity, which did not significantly alter the overall heterogeneity. Results from Egger's test showed no evidence of publication bias (Egger's regression test $P=0.24$; Fig. $3 \mathrm{~d}$ ).

\section{Medical Therapy Versus PCI in CTO Patients: Major Adverse Cardiovascular Event}

A total of 10 studies reported MACE in CTO patients $[13,15$, $17 \cdot \bullet, 18 \cdot \bullet, 19 \bullet \bullet, 21,23,26,28,31]$. Of these, only three out of eight studies supported the use of medical therapy. A pooled analysis of the included studies illustrated that the use of PCI tended to lower risk of MACE when compared to medical therapy (RR 1.25, 95\% CI 1.03-1.51, $P=0.03$; Fig. 2e). Both observational studies (RR $1.25,95 \%$ CI $1.01-1.56, P=$ 0.0004 ) and randomized trials (RR 1.38, 95\% 0.73-2.60, $P=$ 0.33 ) favored PCI in terms of MACE outcomes. Furthermore, $I^{2}$ was $76 \%$ across all studies, indicating a high degree of heterogeneity. Sensitivity analysis excluding one study at a time was performed to locate the origin of the heterogeneity. Doing so did not significantly alter the overall heterogeneity. However, results from Egger's test showed no evidence of publication bias (Egger's regression test $P=0.36$; Fig. 3e).

\section{Medical Therapy Versus PCI in CTO Patients: Cerebral Vascular Accident/Stroke}

Regarding CVA/stroke, only 3 out of 14 studies were found to report this outcome in CTO patients [13, 24, 29]. All three studies reported in favor of PCI over medical therapy. A pooled analysis further supported this, showing that medical therapy has more than twice the risk of causing a CVA/stroke compared to PCI (RR 2.10, 95\% CI $0.84-5.25, P=0.11$; Fig. 2f). However, this result was not statistically significant. $I^{2}$ was $0 \%$ across all studies, indicating a lack of heterogeneity. 


\section{a}

$\begin{array}{cccc}\text { OMT } & \text { PCI } & \begin{array}{c}\text { Risk Ratio } \\ \text { Study or Subgroup }\end{array} \\ \text { Events Total Events } & \text { Total Weight } & \text { M-H, Random, } 95 \% \mathrm{Cl}\end{array}$ 1.1.1 Observational Studies

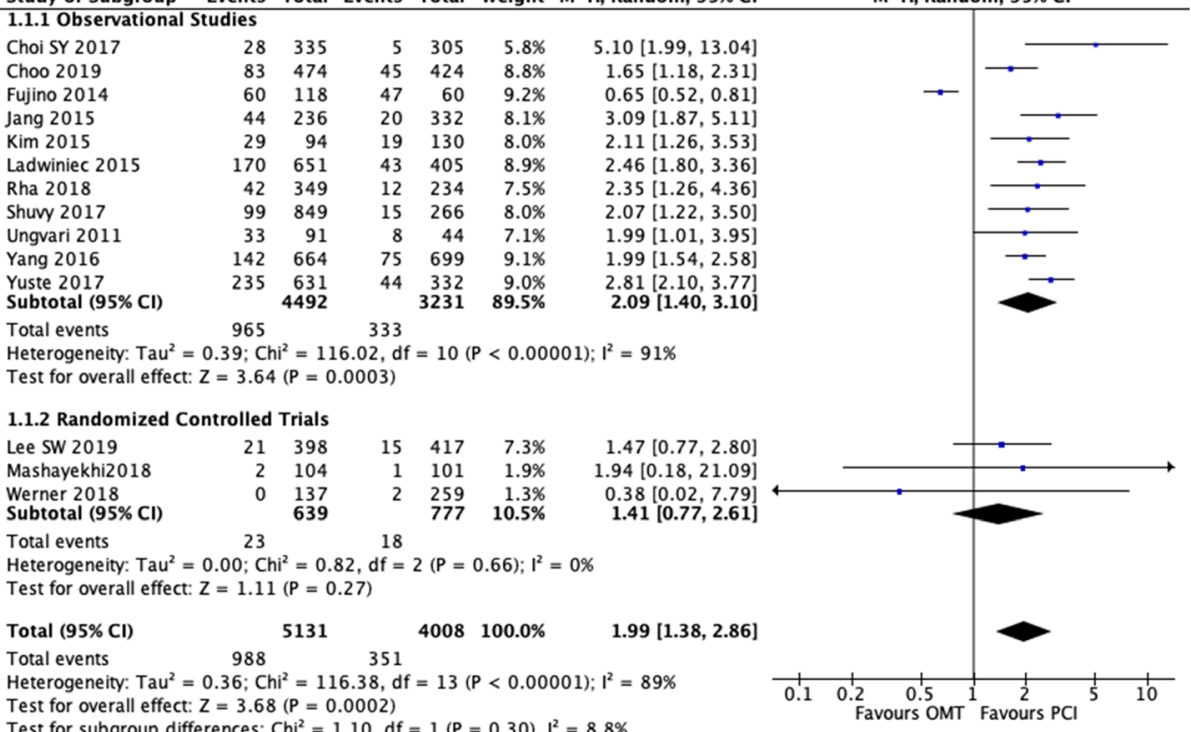

Test for subaroup differences: $\mathrm{Chi}^{2}=1.10 . \mathrm{df}=1(\mathrm{P}=0.30), \mathrm{I}^{2}=8.8 \%$

b

OMT PCl Risk Ratio $-\mathrm{H}$, Fixed, $95 \% \mathrm{Cl}$ Study or Subgroup Events Total Events Total Weight $\mathrm{M}-\mathrm{H}$ $\begin{array}{llllll}13 & 335 & 3 & 305 & 2.0 \% & 3.95[1.14,13.71]\end{array}$ $\begin{array}{lrrrrrr}\text { Choi SY 2017 } & 13 & 335 & 3 & 305 & 2.0 \% & 3.95[1.14,13.71] \\ \text { Guo } 2018 & 19 & 201 & 10 & 125 & 7.8 \% & 1.18[0.57,2.46]\end{array}$ $\begin{array}{lrrrrrr}\text { Guo } 2018 & 19 & 201 & 10 & 125 & 7.8 \% & 1.18[0.57,2.46] \\ \text { Jang 2015 } & 23 & 236 & 7 & 332 & 3.7 \% & 4.62[2.02,10.59]\end{array}$ $\begin{array}{lrrrrrr}\text { Jang 2015 } & 23 & 236 & 7 & 332 & 3.7 \% & 4.62[2.02,10.59] \\ \text { Kim 2015 } & 18 & 94 & 9 & 130 & 4.7 \% & 2.77[1.30,5.88]\end{array}$ \begin{tabular}{lllrrrrr} 
Ladwiniec 2015 & 71 & 651 & 23 & 405 & $17.8 \%$ & $1.97[1.30,5.88]$ \\
\hline & & 28 & 349 & 8 & 234 & $6.0 \%$ & $2.35[1.09,5.02]$
\end{tabular} $\begin{array}{lllllll}\text { Rha } 2018 & 28 & 349 & 8 & 234 & 6.0 \% & 2.35[1.09,5.06]\end{array}$ $\begin{array}{lllllll}\text { Tomasello } 2015 & 39 & 826 & 11 & 776 & 7.1 \% & 3.33[1.72,6.46]\end{array}$ $\begin{array}{llllllll}\text { Yang } 2016 & 66 & 664 & 37 & 699 & 22.7 \% & 1.88[1.27 .777\end{array}$ Yang 2016 Yuste 2017 Subtotal $(95 \% \mathrm{CI})$

Total events $\begin{array}{rrrrrr}66 & 664 & 37 & 699 & 22.7 \% & 1.88[1.27,2.77] \\ 151 & 631 & 27 & 332 & 22.2 \% & 2.94[2.00,4.33]\end{array}$ Heterogeneity: $\mathrm{Chi}^{2}=11.24, \mathrm{df}=8(\mathrm{P}=0.19) ; \mathrm{I}^{2}=29 \%$ Test for overall effect: $Z=9.20(P<0.00001)$

1.2.2 Randomized Controlled Trials

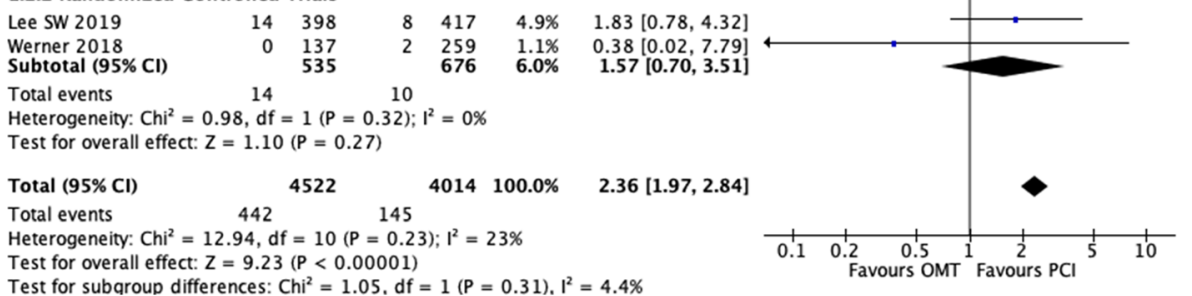

Test for subaroup differences: $\mathrm{Chi}^{2}=1.05, \mathrm{df}=1(\mathrm{P}=0.31), \mathrm{I}^{2}=4.4 \%$

C

$\begin{array}{lccc}\text { OMT } & \text { PCI } & \text { Risk Ratio } \\ \text { Study or Subgroup } & \text { Events } & \text { Total } & \text { Events } \\ \text { Total } & \text { Weight } & \text { M-H, Random, } 95 \% \mathrm{Cl}\end{array}$ 1.4.1 Observational Studies

\begin{tabular}{lrrrrrr} 
Choi SY 2017 & 17 & 335 & 2 & 305 & $7.2 \%$ & $7.74[1.80,33.22]$ \\
Cuo 2018 & 18 & 201 & 11 & 125 & $12.5 \%$ & $1.02[0.50,2.08]$ \\
Jang 2015 & 2 & 236 & 3 & 332 & $5.7 \%$ & $0.94[0.16,5.57]$ \\
Kim 2015 & 5 & 94 & 5 & 130 & $8.7 \%$ & $1.38[0.41,4.64]$ \\
Rha 2018 & 18 & 349 & 4 & 234 & $9.7 \%$ & $3.02[1.03,8.80]$ \\
Tomasello 2015 & 25 & 826 & 8 & 776 & $11.9 \%$ & $2.94[1.33,6.47]$ \\
Yang 2016 & 12 & 664 & 11 & 699 & $11.7 \%$ & $1.15[0.51,2.58]$ \\
Yuste 2017 & 151 & 631 & 27 & 332 & $15.0 \%$ & $2.94[2.00,4.33]$ \\
Subtotal (95\% Cl) & \multicolumn{7}{c}{3336} & & 2933 & $\mathbf{8 2 . 5 \%}$ & $2.04[1.31,3.20]$ \\
Total events & 248 \\
Heterogeneity: $\mathrm{Tau}^{2}=0.19 ; \mathrm{Chi}^{2}=14.43, \mathrm{df}=7(\mathrm{P}=0.04) ; \mathrm{I}^{2}=52 \%$
\end{tabular}

Test for ove

1.4.2 Randomized Controlled Trials

$\begin{array}{lrrrrr}\text { Lee SW 2019 } & 34 & 398 & 47 & 417 & 14.8 \% \\ \text { Werner 2018 } & 0 & 137 & 5 & 259 & 2.7 \% \\ \text { Subtotal (95\% CI) } & & 535 & & \mathbf{6 7 6} & \mathbf{1 7 . 5 \%} \\ \text { Total events } & 34 & & 52 & & \end{array}$

Total events

34 52

Heterogeneity. $\mathrm{Tau}^{2}=0.02 ; \mathrm{Chi}^{2}=1.02, \mathrm{df}=1(\mathrm{P}=0.31) ; \mathrm{I}^{2}=2 \%$ est for overall effect: $Z=1.26(P=0.21)$ $\begin{array}{lllll}\text { Total }(95 \% \mathrm{CI}) & 3871 & 3609 & 100.0 \% & 1.65[0.97,2.78]\end{array}$ 282 123

Heterogeneity: $\mathrm{Tau}^{2}=0.44 ; \mathrm{Chi}^{2}=35.14, \mathrm{df}=9(\mathrm{P}<0.0001) ; \mathrm{I}^{2}=74 \%$

Test for overall effect: $Z=1.86(P=0.06)$

Test for subaroup differences: $\mathrm{Chi}^{2}=9.20 . \mathrm{df}=1(\mathrm{P}=0.002) . \mathrm{I}^{2}=89.1 \%$

$0.76[0.50,1.15]$ $0.17[0.01,3.07]$ M-H, Fixed, $95 \% \mathrm{Cl}$

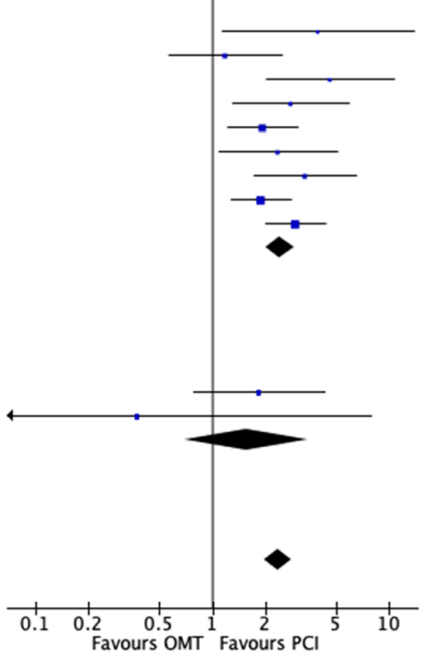


Fig. 2 (a) Forest plots comparing risk of all-cause mortality events between OMT and PCI in patients with CTO. (b) Forest plots comparing risk of cardiac death between OMT and PCI in patients with CTO. (c) Forest plots comparing risk of CVA/stroke events between OMT and PCI in patients with CTO. (d) Forest plots comparing risk of myocardial infarction between OMT and PCI in patients with CTO. (e) Forest plots comparing risk of repeated revascularization events between OMT and PCI in patients with CTO. (f) Forest plots comparing risk of MACE events between OMT and PCI in patients with CTO. (g) Forest plots comparing risk of MACCE events between OMT and PCI in patients with $\mathrm{CTO}$

Results from Egger's test showed no evidence of publication bias (Egger's regression test $P=0.22$ ).

\section{Medical Therapy Versus PCI in CTO Patients: MACCE}

Lastly, the outcome of MACCE was only reported in two studies [24, 29]. Both studies individually favored the use of PCI to avoid such events, which was supported by a pooled analysis (RR 2.47, 95\% CI 1.52-4.02, $P=$ 0.0003 ; Fig. $2 \mathrm{~g}$ ). $I^{2}$ was $56 \%$ across all studies, indicating a moderate level of heterogeneity. However, an exclude-one sensitivity analysis could not be done, as there are only two studies involved. Similarly, Begg's and Egger's analysis could not be used due to the limited number of studies involved.

\section{Univariate Meta-Regression Analysis of All Outcome Measures}

A univariate meta-regression analysis was conducted using all common covariates across the 17 studies included for four outcome measures, which were allcause mortality, cardiac death, MI, and repeat revascularization. CVA/stroke, MACE, and MACCE outcomes were omitted from regression analysis due to a lack of reporting from relevant articles. Covariates used were mean age, male sex, hypertension, diabetes mellitus, dyslipidemia, smoking, prior PCI, LAD lesion, and calcification. Results of the meta-regression are shown in Table 2 accordingly. No variables were found to independently moderate all-cause mortality and cardiac death outcomes. However, mean age, hypertension, smoking, LAD lesion, and the presence of calcification were also found to be a significant moderator of MI while repeat revascularization was moderated by male gender, diabetes mellitus, smoking, and prior PCI. Apart from these, none of the other factors moderated cardiac death, MI, repeat revascularization, or all-cause mortality outcomes. Slope coefficients did not differ significantly from zero $(P>0.05)$.

\section{Discussion}

This systematic review and meta-analysis included 17 cohort studies with a total of 11,493 patients, comparing the use of medical therapy and PCI in patients with known CTO. A total of seven outcomes including all-cause mortality, cardiac death, MI, repeat revascularization, MACE, CVA/stroke, and MACCE were assessed. A subsequent univariate metaregression was also conducted to evaluate the impact of covariates on outcome measures. Our pooled analysis found a statistically significant association between PCI and lower risk of all-cause mortality, cardiac death, MI, MACE, and MACCE when compared to medical therapy. However, this was driven predominantly by the observational cohorts. The randomized studies showed a potential improvement with PCI in overall mortality, cardiac death, repeat revascularization, and MACE; however, no statistical significance was achieved. PCI tended to reduce CVA/stroke outcomes when compared to medical therapy, but the results did not reach significance, which may be due to the limited sample size. On the other hand, MACE which included admission for heart failure and non-fatal strokes was favored by PCI. A non-significant reduced risk of repeat revascularization was found to be associated with medical therapy $(P>0.05)$. This is likely due to further activation of the inflammatory pathway, which leads to the development of intimal hyperplasia and subsequent restenosis following PCI [32]. In our univariate regression analysis, there were no significant moderators of all-cause mortality and cardiac death. This is not in keeping with a large Swedish study involving 14,441 patients, which reported that presence of a CTO was associated with the highest risk of mortality in patients less than 60 years of age compared to the low risk found in octogenarians [33]. However, the lack of association between diabetes and sex is supported by another study [33]. Interestingly, our univariate analysis also showed hypertension, dyslipidemia, and smoking to be nonsignificantly linked with all-cause mortality. As for MI, it is surprising that diabetes mellitus was found to be a nonsignificant moderator given the extensive literature supporting this correlation [34] while mean age, hypertension, smoking, having LAD lesions, and calcification were significant moderators.

Our findings differ from those of a previous metaanalysis comparing medical therapy and PCI in patients with stable coronary artery disease. The latter reported that PCI was not significantly better than optimal medical therapy in reducing risk of all-cause mortality, cardiac death, and MI [35]. Similar findings were noted in the landmark Courage Trial where PCI was not found to be superior to medical therapy but CTO patients were not represented in this study and patients would receive more intense medical therapy than what would be expected in reality [36]. Another meta-analysis confirmed that 
d

OMT PCI Risk Ratio

Study or Subgroup Events Total Events Total Weight $\mathrm{M}-\mathrm{H}$, Random, $95 \% \mathrm{CI}$ 1.5.1 Observational Studies

\begin{tabular}{|c|c|c|c|c|c|c|}
\hline Choi SY 2017 & 38 & 335 & 51 & 305 & $12.1 \%$ & $0.68[0.46,1.00]$ \\
\hline Guo 2018 & 24 & 201 & 26 & 125 & $10.8 \%$ & $0.57[0.35,0.9$ \\
\hline Jang 2015 & 37 & 236 & 31 & 332 & $11.5 \%$ & $1.68[1.07,2.6$ \\
\hline Kim 2015 & 18 & 94 & 15 & 130 & $9.5 \%$ & $1.66[0.88,3.1$ \\
\hline Ladwiniec 2015 & 76 & 651 & 96 & 405 & $13.3 \%$ & $0.49[0.37,0.6$ \\
\hline Rha 2018 & 46 & 349 & 49 & 234 & $12.4 \%$ & $0.63[0.44,0.9$ \\
\hline $\begin{array}{l}\text { Yang } 2016 \\
\text { Subtotal }(95 \% \mathrm{Cl})\end{array}$ & 109 & $\begin{array}{r}664 \\
2530\end{array}$ & 105 & $\begin{array}{r}699 \\
2230\end{array}$ & $\begin{array}{l}13.5 \% \\
83.1 \%\end{array}$ & $\begin{array}{l}1.09[0.85,1.4 \\
0.85[0.59,1.2\end{array}$ \\
\hline Total events & 348 & & 373 & & & \\
\hline
\end{tabular}

Total events
Heterogeneity: Tau $^{2}=0.19 ; \mathrm{Chi}^{2}=37.87, \mathrm{df}=6(\mathrm{P}<0.00001) ; \mathrm{I}^{2}=84 \%$

Test for overall effect: $Z=0.92(P=0.36)$

1.5.2 Randomized Controlled Trials
Lee SW 2019
Mashayekhi2018
Subtotal $(95 \% \mathrm{Cl})$
Total events
$\begin{array}{ll}42 & 398 \\ 14 & 104 \\ & 502\end{array}$ 56
$\begin{array}{lll}46 & 417 & 12.1 \%\end{array}$
$\begin{array}{lll}3 & 101 & 4.8 \% \\ & 518 & 16.9 \%\end{array}$
$0.96[0.64,1.42]$
$4.53[1.34,15.30]$
Heterogeneity: $\mathrm{Tau}^{2}=1.02 ; \mathrm{Chi}^{2}=5.79, \mathrm{df}=1(\mathrm{P}=0.02) ; \mathrm{I}^{2}=83 \%$
Test for overall effect: $Z=0.80(P=0.42)$
Total $(95 \% \mathrm{Cl}) \quad \begin{aligned} & 3032 \\ & \text { Total events }\end{aligned} 404 \quad 2748 \quad 100.0 \% \quad 0.93[0.67,1.29]$
Heterogeneity: $\mathrm{Tau}^{2}=0.19 ; \mathrm{Chi}^{2}=46.19, \mathrm{df}=8(\mathrm{P}<0.00001) ; \mathrm{I}^{2}=83 \%$
Test for overall effect: $\mathrm{Z}=0.42(\mathrm{P}=0.67)$
Test for subaroup differences: $\mathrm{Chi}^{2}=0.98, \mathrm{df}=1(\mathrm{P}=0.32), \mathrm{I}^{2}=0 \%$
Test for subaroup differences: $\mathrm{Chi}^{2}=0.98, \mathrm{df}=1(\mathrm{P}=0.32), \mathrm{I}^{2}=0 \%$

e

OMT

PCI

Risk Ratio

Study or Subgroup Events Total Events Total Weight M-H, Random, $95 \% \mathrm{Cl}$ 1.6.1 Observational Studies

\begin{tabular}{lrrrrrr} 
Choi SY 2017 & 65 & 335 & 55 & 305 & $11.1 \%$ & 1.08 \\
Fujino 2014 & 103 & 118 & 43 & 60 & $14.3 \%$ & 1.22 \\
Guo 2018 & 44 & 201 & 37 & 125 & $10.0 \%$ & 0.74 \\
Jang 2015 & 59 & 236 & 38 & 332 & $10.1 \%$ & 2.18 \\
Rha 2018 & 86 & 349 & 59 & 234 & $11.9 \%$ & 0.98 \\
Song 2011 & 28 & 68 & 23 & 119 & $8.4 \%$ & 2.13 \\
Yang 2016 & 170 & 664 & 141 & 699 & $13.8 \%$ & 1.27 \\
Subtotal (95\% Cl) & \multicolumn{7}{c}{1971} & & 1874 & $79.6 \%$ & 1.25 \\
Total events & 555 & & \\
Heterogeneity: $\mathrm{Tau}^{2}=0.06 ; \mathrm{Chi}^{2}=24.81, \mathrm{df}=6(\mathrm{P}=0.0004) ; \mathrm{I}^{2}=76 \%$ \\
Test for overall effect: $\mathrm{Z}=2.01(\mathrm{P}=0.04)$
\end{tabular}

Test for overall effect: $Z=2.01(P=0.04)$

1.6.2 Randomized Controlled Trials

\begin{tabular}{|c|c|c|c|c|c|c|}
\hline Lee SW 2019 & 100 & 398 & 110 & 417 & $13.1 \%$ & $0.95[0.75,1.20]$ \\
\hline Mashayekhi2018 & 17 & 104 & 6 & 101 & $3.6 \%$ & $2.75[1.13,6.70]$ \\
\hline $\begin{array}{l}\text { Werner } 2018 \\
\text { Subtotal }(95 \% \mathrm{CI})\end{array}$ & 8 & $\begin{array}{l}137 \\
639\end{array}$ & 11 & $\begin{array}{l}259 \\
777\end{array}$ & $\begin{array}{r}3.7 \% \\
20.4 \%\end{array}$ & $\begin{array}{c}1.37[0.57,3.34] \\
1.38[0.73,2.60]\end{array}$ \\
\hline \multicolumn{7}{|c|}{$\begin{array}{l}\text { Total events } \mathrm{Tau}^{2}=0.20 ; \mathrm{Chi}^{2}=5.59, \mathrm{df}=2(\mathrm{P}=0.06) ; \mathrm{I}^{2}=64 \% \\
\text { Heterogeneity: } \\
\text { Test for overall effect: } \mathrm{Z}=0.98(\mathrm{P}=0.33)\end{array}$} \\
\hline Total $(95 \% \mathrm{CI})$ & \multicolumn{3}{|c|}{2610} & 2651 & $100.0 \%$ & $1.25[1.03,1.51]$ \\
\hline $\begin{array}{l}\text { Total events } \\
\text { Heterogeneity: Tau } \\
\text { Test for overall effe }\end{array}$ & $\begin{aligned} & 680 \\
& 06 ; C h \\
&= 2.24\end{aligned}$ & 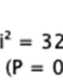 & 523 & $9(P=$ & $=0.000$ & $\%$ \\
\hline
\end{tabular}

Test for subqroup differences: $C h i^{2}=0.08, \mathrm{df}=1(\mathrm{P}=0.78), \mathrm{I}^{2}=0 \%$

$1.08[0.78,1.49]$

$22[1.02,1.45]$

$0.74[0.51,1.08]$

$.18[1.51,3.17]$

$13[1.34,3.39]$

$1.25[1.01,1.56]$$$
76 \%
$$ 

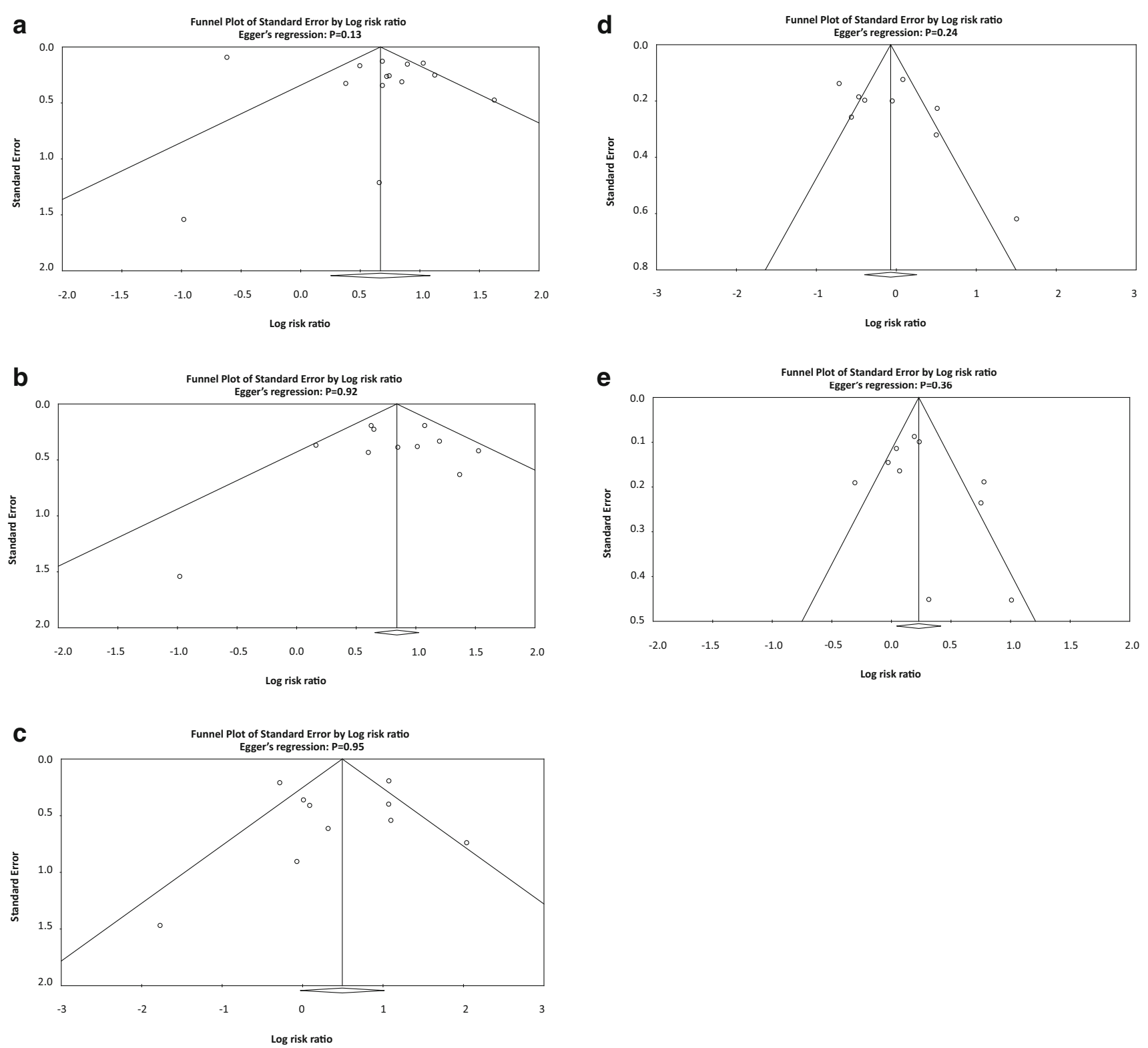

Fig. 3 (a) Trim-and-fill funnel plots with Egger's regression test of allcause mortality comparing between OMT and PCI in patients with CTO. (b) Trim-and-fill funnel plots with Egger's regression test of cardiac death comparing between OMT and PCI in patients with CTO. (c) Trim-and-fill funnel plots with Egger's regression test of CVA/stroke comparing

successful PCIs in CTO patients pertain to higher longterm survival along with reduced risk of developing subsequent MI [37]. Recently, a similar meta-analysis looking only into five articles stated that the PCI was significantly associated with reduced risk of all-cause mortality, cardiac death, and MACE in CTO patients. This result was further supported in their "infarct-related area" subgroup analysis [38]. In contrast, our metaanalysis utilized 17 studies with a significantly greater patient population. As such, our results favoring PCI in

between OMT and PCI in patients with CTO. (d) Trim-and-fill funnel plots with Egger's regression test of MI comparing between OMT and PCI in patients with CTO. (e) Trim-and-fill funnel plots with Egger's regression test of repeated revascularization comparing between OMT and $\mathrm{PCI}$ in patients with $\mathrm{CTO}$

CTO should be interpreted in the knowledge that this is driven mainly by the outcomes in the observational cohorts and that the RCT failed to reach significance. Nonetheless, even in the RCT, a non-significant trend in benefit was seen with PCI groups indicating perhaps that more RCTs are needed for a definite answer. Despite this, our meta-analysis suggests that at the very least, there is no evidence to advice against PCI in CTO at present and possibly there might be some benefit. 
Table 2 Multivariate metaregression analysis of outcome measures

\begin{tabular}{|c|c|c|c|c|c|c|}
\hline \multicolumn{7}{|c|}{ Univariate meta-regression } \\
\hline \multirow[t]{2}{*}{ Variable } & \multirow[t]{2}{*}{ Slope coefficient } & \multirow[t]{2}{*}{ SE } & \multirow[t]{2}{*}{$Z$ value } & \multirow[t]{2}{*}{$P$ value } & \multicolumn{2}{|l|}{$95 \% \mathrm{CI}$} \\
\hline & & & & & Lower limit & Upper limit \\
\hline \multicolumn{7}{|l|}{ All-cause mortality } \\
\hline Mean age (years) & -0.0601 & 0.109 & -0.553 & 0.580 & -0.273 & 0.153 \\
\hline Male gender & -0.969 & 3.102 & -0.312 & 0.755 & -7.048 & 5.111 \\
\hline Hypertension & -1.628 & 1.849 & -0.881 & 0.378 & -5.251 & 1.995 \\
\hline Diabetes mellitus & 0.0376 & 1.558 & 0.0241 & 0.981 & -3.016 & 3.091 \\
\hline Dyslipidemia & -1.086 & 0.877 & -1.239 & 0.215 & -2.804 & 0.632 \\
\hline Smoking & 0.933 & 1.082 & 0.863 & 0.388 & -1.187 & 3.054 \\
\hline \multicolumn{7}{|l|}{ Cardiac death } \\
\hline Mean age (years) & 0.0799 & 0.0523 & 1.529 & 0.126 & -0.0225 & 0.182 \\
\hline Male gender & 1.049 & 1.877 & -2.629 & 0.576 & -2.629 & 4.728 \\
\hline Hypertension & 1.057 & 1.262 & 0.837 & 0.402 & -1.417 & 3.532 \\
\hline Diabetes mellitus & 0.692 & 0.893 & 0.775 & 0.438 & -1.058 & 2.443 \\
\hline Dyslipidemia & 0.0645 & 0.613 & 0.105 & 0.916 & -1.137 & 1.266 \\
\hline Myocardial infarction & -0.0875 & 0.810 & -0.108 & 0.914 & -1.674 & 1.499 \\
\hline \multicolumn{7}{|l|}{ Myocardial infarction } \\
\hline Mean age (years)* & 0.257 & 0.0517 & 4.969 & $<0.0001$ & 0.155 & 0.358 \\
\hline Male gender & -1.504 & 5.000 & -0.301 & 0.764 & -11.301 & 8.293 \\
\hline Hypertension* & 8.026 & 2.275 & 3.528 & 0.000419 & 3.567 & 12.486 \\
\hline Diabetes mellitus & 1.106 & 3.115 & 0.355 & 0.722 & -4.999 & 7.212 \\
\hline Smoking* & 4.611 & 1.023 & 4.506 & $<0.0001$ & 2.605 & 6.617 \\
\hline LAD lesion* & 4.907 & 2.481 & 1.978 & 0.0480 & 0.0440 & 9.769 \\
\hline Calcification* & -6.476 & 3.751 & -1.726 & 0.0843 & -13.828 & 0.876 \\
\hline \multicolumn{7}{|l|}{ Repeat revascularization } \\
\hline Mean age (years) & -0.01 & 0.133 & -0.751 & 0.452 & -0.361 & 0.161 \\
\hline Male gender* & 6.288 & 2.243 & 2.803 & 0.00506 & 1.891 & 10.684 \\
\hline Hypertension & -2.913 & 2.107 & 1.383 & 0.167 & -1.216 & 7.043 \\
\hline Diabetes mellitus* & 2.808 & 1.0142 & 2.769 & 0.00563 & 0.820 & 4.796 \\
\hline Smoking* & -2.388 & 0.605 & -3.950 & $<0.0001$ & -3.573 & -1.203 \\
\hline Prior PCI* & 4.151 & 1.775 & 2.339 & 0.0193 & 0.673 & 7.630 \\
\hline
\end{tabular}

\section{Limitations}

A moderate to high degree of heterogeneity was identified during analysis of some outcome measures and we thus performed an exclude-one sensitivity analysis to locate the source of heterogeneity and rectify this. In addition, one of the areas of growing interest in CTO PCI work is to appropriately select patients by demonstrating objective evidence of reversible ischemia corresponding to the territory of the $\mathrm{CTO}$, rather than simply relying on angina as a marker for this [39]. Unfortunately, the inclusion criteria from the studies used included "angina or reversible ischemia." Therefore, we were not able to consider a specific subgroup of patients who had evidence of reversible ischemia on functional testing and viable myocardium. Finally, we have considered the observational and randomized studies together in the analysis but also separately. Although the observational studies favored the PCI quite significantly, this was not statistically seen when only the fewer randomized studies were considered; this indicates, however, that a true beneficial effect could well have been observed if more randomized studies were available to meta-analyze.

\section{Future Directions}

The unmet clinical question is whether randomized studies in patients who have objective evidence of reversible ischemia, which can also be quantified, might benefit from PCI. Although it can be expected that patients with a higher burden of reversible ischemia and higher percentage of viable 
myocardium are likely to benefit more from percutaneous intervention, new evidence is needed to answer this question [40].

\section{Conclusions}

The use of PCI in patients with CTO was found to be associated with lower risk of all outcome measures except repeat revascularization, a result driven predominantly by the observational cohorts as the randomized studies appeared to show a smaller benefit but were underpowered to statistically confirm that. However, statistically significant results were seen only for all-cause mortality, cardiac death, MI, MACE, and MACCE in pooled analysis and not in the RCT-specific subgroup analysis. Our results suggest that $\mathrm{PCI}$ could therefore be considered in the CTO in patients with angina or evidence of reversible ischemia. Larger randomized clinical trials can address an individualized personalized approach incorporating the risk and complexity associated with CTO PCI, the burden of ischemia, and myocardial viability.

Acknowledgments G.T. would like to thank the Croucher Foundation of Hong Kong for their support. V.S.V. would like to thank Norfolk Heart Trust, UK for their support.

Guarantor G.T. is the guarantor of this manuscript.

\section{Compliance with Ethical Standards}

Conflict of Interest K.H.C.L., G.W., M.G., T.L., G.L., Y.X., J.H., L.N.F., A.C.S., S.E., G.T., and V.S.V. declare that they have no conflict of interest.

Human and Animal Rights and Informed Consent This article does not contain any studies with human or animal subjects performed by any of the authors.

Open Access This article is distributed under the terms of the Creative Commons Attribution 4.0 International License (http:// creativecommons.org/licenses/by/4.0/), which permits unrestricted use, distribution, and reproduction in any medium, provided you give appropriate credit to the original author(s) and the source, provide a link to the Creative Commons license, and indicate if changes were made.

\section{References}

Papers of particular interest, published recently, have been highlighted as:

- Of importance

•. Of major importance

1. Windecker S, Kolh P, Alfonso F, Collet JP, Cremer J, Falk V, et al. 2014 ESC/EACTS guidelines on myocardial revascularization: the task force on myocardial revascularization of the European Society of Cardiology (ESC) and the European Association for CardioThoracic Surgery (EACTS) developed with the special contribution of the European Association of Percutaneous Cardiovascular Interventions (EAPCI). Eur Heart J. 2014;35(37):2541-619.

2. Christofferson RD, Lehmann KG, Martin GV, Every N, Caldwell JH, Kapadia SR. Effect of chronic total coronary occlusion on treatment strategy. Am J Cardiol. 2005;95(9):1088-91.

3. Fefer P, Knudtson ML, Cheema AN, Galbraith PD, Osherov AB, Yalonetsky S, et al. Current perspectives on coronary chronic total occlusions: the Canadian Multicenter Chronic Total Occlusions Registry. J Am Coll Cardiol. 2012;59(11):991-7.

4. Jeroudi OM, Alomar ME, Michael TT, El Sabbagh A, Patel VG, Mogabgab O, et al. Prevalence and management of coronary chronic total occlusions in a tertiary Veterans Affairs hospital. Catheter Cardiovasc Interv. 2014;84(4):637-43.

5. Brilakis ES, Banerjee S, Karmpaliotis D, Lombardi WL, Tsai TT, Shunk KA, et al. Procedural outcomes of chronic total occlusion percutaneous coronary intervention: a report from the NCDR (National Cardiovascular Data Registry). JACC Cardiovasc Interv. 2015;8(2):245-53.

6. Azzalini L, Jolicoeur EM, Pighi M, Millan X, Picard F, Tadros VX, et al. Epidemiology, management strategies, and outcomes of patients with chronic total coronary occlusion. Am J Cardiol. 2016;118(8):1128-35.

7. Anderson HV, Shaw RE, Brindis RG, Hewitt K, Krone RJ, Block $\mathrm{PC}$, et al. A contemporary overview of percutaneous coronary interventions. The American College of Cardiology-National Cardiovascular Data Registry (ACC-NCDR). J Am Coll Cardiol. 2002;39(7):1096-103.

8. Werner GS, Gitt AK, Zeymer U, Juenger C, Towae F, Wienbergen $\mathrm{H}$, et al. Chronic total coronary occlusions in patients with stable angina pectoris: impact on therapy and outcome in present day clinical practice. Clin Res Cardiol. 2009;98(7):435-41.

9. Chi WK, Gong M, Bazoukis G, Yan BP, Letsas KP, Liu T, et al. Impact of coronary artery chronic total occlusion on arrhythmic and mortality outcomes. A systematic review and meta-analysis. JACC Clin Electrophysiol. 2018;4(9):1214-1223

10. Levine GN, Bates ER, Blankenship JC, Bailey SR, Bittl JA, Cercek $\mathrm{B}$, et al. $2011 \mathrm{ACCF} / \mathrm{AHA} / \mathrm{SCAI}$ guideline for percutaneous coronary intervention: a report of the American College of Cardiology Foundation/American Heart Association Task Force on Practice Guidelines and the Society for Cardiovascular Angiography and Interventions. Circulation. 2011;124(23):e574-651.

11. Kearney K, Hira RS, Riley RF, Kalyanasundaram A, Lombardi WL. Update on the management of chronic total occlusions in coronary artery disease. Curr Atheroscler Rep. 2017;19(4):19.

12. Henriques JP, Hoebers LP, Ramunddal T, Laanmets P, Eriksen E, Bax M, et al. Percutaneous intervention for concurrent chronic total occlusions in patients with STEMI: the EXPLORE trial. J Am Coll Cardiol. 2016;68(15):1622-32.

13. Choi SY, Choi BG, Rha SW, Baek MJ, Ryu YG, Park Y, et al. Percutaneous coronary intervention versus optimal medical therapy for chronic total coronary occlusion with well-developed collaterals. J Am Heart Assoc. 2017;13;6(9).

14. Choo EH, Koh YS, Seo SM, Lee JM, Kim HY, Park HJ, et al. Comparison of successful percutaneous coronary intervention versus optimal medical therapy in patients with coronary chronic total occlusion. J Cardiol. 2019;73(2):156-62.

15. Fujino M, Ishihara M, Honda S, Kawakami S, Yamane T, Nagai T, et al. Long-Term Follow-Up of Patients with Acute Myocardial Infarction with Chronic Total Occlusion in the Non-Infarct Related Artery. Circulation. 2014;130(suppl_2).

16. Ladwiniec A, Allgar V, Thackray S, Alamgir F, Hoye A. Medical therapy, percutaneous coronary intervention and prognosis in patients with chronic total occlusions. Heart. 2015;101(23):1907-14 A well-reported retrospective study. 
17.• Lee SW, Lee PH, Ahn JM, Park D-W, Yun SC, Han S, et al. Randomized Trial Evaluating Percutaneous Coronary Intervention for the Treatment of Chronic Total Occlusion.Circulation. 2019;139(14):1674-83.

18. Mashayekhi K, Nuhrenberg TG, Toma A, Gick M, Ferenc M, Hochholzer $\mathrm{W}$, et al. A randomized trial to assess regional left ventricular function after stent implantation in chronic total occlusion: the REVASC trial. JACC Cardiovasc Interv. 2018;11(19): 1982-91.

19.• Werner GS, Martin-Yuste V, Hildick-Smith D, Boudou N, Sianos $\mathrm{G}$, Gelev V, et al. A randomized multicentre trial to compare revascularization with optimal medical therapy for the treatment of chronic total coronary occlusions. Eur Heart J. 2018;39(26):2484 93 A recent randomised trial on management of CTO.

20. Cheney A, Kearney KE, Lombardi W. Sex-based differences in chronic total occlusion management. Curr Atheroscler Rep. 2018;20(12):60.

21. Guo L, Zhong L, Chen K, Wu J, Huang RC. Long-term clinical outcomes of optimal medical therapy vs. successful percutaneous coronary intervention for patients with coronary chronic total occlusions. Hell J Cardiol. 2018;59(5):281-7.

22. Hwang JW, Yang JH, Choi SH, Hwang JK, Jang WJ, Hahn JY, et al. Optimal medical therapy may be a better initial strategy in patients with chronic total occlusion of a single coronary artery. Int $\mathrm{J}$ Cardiol. 2016;210:56-62.

23. Jang WJ, Yang JH, Choi SH, Song YB, Hahn JY, Choi JH, et al. Long-term survival benefit of revascularization compared with medical therapy in patients with coronary chronic total occlusion and well-developed collateral circulation. JACC Cardiovasc Interv. 2015;8(2):271-9.

24. Kim BS, Yang JH, Jang WJ, Song YB, Hahn JY, Choi JH, et al. Clinical outcomes of multiple chronic total occlusions in coronary arteries according to three therapeutic strategies: bypass surgery, percutaneous intervention and medication. Int $\mathrm{J}$ Cardiol. 2015;197:2-7.

25. Martin Yuste V, Gonzalez IF, Flores E, Hernandez M, Vazquez S, Robles C, et al. TCT-564 Monocenter registry of 1248 consecutive patients with a coronary chronic total occlusion: predictor factors of cardiac death. J Am Coll Cardiol. 2017;70(18 Supplement):B233B4.

26. Rha S-W, Choi SY, Choi BG, Byun JK, Mashaly A, Park Y, et al. Impact of successful percutaneous coronary intervention on chronic total occlusion outcomes in multi-vessel disease patients. J Am Coll Cardiol. 2018;71(11 Supplement):A1274.

27. Shuvy M, Qiu F, Chee ATA, Graham JJ, Abuzeid W, Buller C, et al. Management of chronic total coronary occlusion in stable ischemic heart disease by percutaneous coronary intervention versus coronary artery bypass grafting versus medical therapy. Am J Cardiol. 2017;120(5):759-64.

28. Song M, Yun HE, Lee SH, Lee SR, Rhee KS, Kim WH, et al. Syntax score can predict long-term clinical outcomes in patients with chronic total occlusion. J Am Coll Cardiol. 2011;1:E962.
29. Tomasello SD, Boukhris M, Giubilato S, Marza F, Garbo R, Contegiacomo G, et al. Management strategies in patients affected by chronic total occlusions: results from the Italian registry of chronic total occlusions. Eur Heart J. 2015;36(45):3189-98.

30. Ungvari $\mathrm{T}$, Ismail $\mathrm{H}$, Shah $\mathrm{N}$, Khan $\mathrm{F}$, Ahmed $\mathrm{D}$, Loh $\mathrm{H}$, et al. Impact of therapy (medical versus revascularization) on the longterm survival of patients with coronary disease including a chronic total occlusion. Am J Cardiol. 2011;1:14A-5A.

31. Yang JH, Kim BS, Jang WJ, Ahn J, Park TK, Song YB, et al. Optimal medical therapy vs. percutaneous coronary intervention for patients with coronary chronic total occlusion - a propensitymatched analysis. Circulation. 2016;80(1):211-7.

32. Toutouzas K, Colombo A, Stefanadis C. Inflammation and restenosis after percutaneous coronary interventions. Eur Heart J. 2004;25(19):1679-87.

33. Råmunddal T, Hoebers LP, Henriques JPS, Dworeck C, Angerås O, Odenstedt J, et al. Prognostic impact of chronic total occlusions: a report from SCAAR (Swedish Coronary Angiography and Angioplasty Registry). JACC Cardiovasc Interv. 2016;9(15): 1535-44.

34. Chiha M, Njeim M, Chedrawy EG. Diabetes and coronary heart disease: a risk factor for the global epidemic. Int J Hypertens. 2012;2012:697240.

35. Pursnani S, Korley F, Gopaul R, Kanade P, Chandra N, Shaw RE, et al. Percutaneous coronary intervention versus optimal medical therapy in stable coronary artery disease: a systematic review and meta-analysis of randomized clinical trials. Circ Cardiovasc Interv. 2012;5(4):476-90.

36. Boden WE, O'Rourke RA, Teo KK, Hartigan PM, Maron DJ, Kostuk WJ, et al. Optimal medical therapy with or without PCI for stable coronary disease. N Engl J Med. 2007;356(15):1503-16.

37. Gao L, Wang Y, Liu Y, Cao F, Chen Y. Long-term clinical outcomes of successful revascularization with drug-eluting stents for chronic total occlusions: a systematic review and meta-analysis. Catheter Cardiovasc Interv. 2017;89(S1):574-81.

38. Ma Y, Li D, Li J, Li Y, Bai F, Qin F, et al. Percutaneous coronary intervention versus optimal medical therapy for patients with chronic total occlusion: a meta-analysis and systematic review. J Thorac Dis. 2018;10(5):2960-7.

39. Pica S, Di Giovine G, Bollati M, Testa L, Bedogni F, Camporeale A, et al. Cardiac magnetic resonance for ischaemia and viability detection. Guiding patient selection to revascularization in coronary chronic total occlusions: The CARISMA_CTO study design. Int J Cardiol. 2018;272:356-62.

40. Merinopoulos I, Corballis N, Eccleshall SC, Vassiliou VS. Risk of sudden cardiac death: are coronary chronic total occlusions an additional risk factor? World J Cardiol. 2018;10(12):250-3.

Publisher's Note Springer Nature remains neutral with regard to jurisdictional claims in published maps and institutional affiliations. 